\title{
How Do Translation Students' Cognitive Efforts Vary? - An Answer in Consideration of Pauses
}

\author{
Mehmet Yildiz \\ Faculty of Arts and Sciences, Çanakkale Onsekiz Mart University \\ Terzioğlu Campus, Room: 23, 17100, Çanakkale, Turkey
}

\begin{abstract}
Note: This paper has been derived from the author's doctoral dissertation, which is titled "Assessment of Translation Trainees' Translation Competencies within the Scope of Specialized Translation" and was financially supported by the Scientific and Technological Research Council of Turkey (Fellowship\#: 1059B141401063).

\section{Abstract}

Cognitive dynamics of translators as a translational phenomenon have drawn much scholarly attention over the last three decades and this non-physical phenomenon has been investigated in view of textual and non-textual observable data. The present study operationalizes pauses as observable non-textual data to investigate cognitive effort that translation students invest in as they translate. To this end, the author utilized a keylogger - Translog II - to obtain pause-related data, i.e. number of pauses and length of pauses. The sample consists of 78 first-, second-, third-, and fourth-year translation students studying in the Department of Translation and Interpreting in English at Istanbul University. The data were collected from the participants in two sessions, October 2013 and May 2014, in which they were invited to translate two excerpts from two different user's manuals. The results revealed that translation students tend to invest not only higher levels of but also varying degrees of cognitive efforts during translation as they are more exposed to translation training.
\end{abstract}

Keywords: Number of pauses, Length of pauses, Cognitive effort, Translation students, Keylogging,

DOI: $10.7176 / \mathrm{JEP} / 11-2-05$

Publication date: January $31^{\text {st }} 2020$

\section{Introduction}

Translation process is not an uninterrupted flow of textual production rather a behavioral potpourri of several activities, such as reading, understanding, writing/typing, deleting, revising, and pausing with underlying cognitive processes. The components in this non-exhaustive list result either in or from decision-making. Before writing/typing the very first letter of their target texts and even before reading, translators typically make macrolevel decisions and as they write, their decisions occur at micro-level. Micro-level decisions supposedly made in congruence with macro-level decisions are products of decisions between at least two choices, a process whereby a translational choice is singled out over the other(s). This mental-level processing leads to a material-level production (Schilperoord, 1996: 8). Schilperoord (1996) states that textual production consists of "successive production increments", each of which "corresponds with its own mental structure". He believes that each increment is produced as a result of an "attention state" (1996: 9), which suggests that the end of an increment should mark the end of the attention state and a subsequent production increment should point to the beginning of a new attention state. According to Schilperoord (1996), what come into play between two subsequent increments, and of course two mental structures, are pauses, which "are behavioural[sic] reflections of the cognitive processes involved in changing attentional stages" (p. 9).

As Schilperood puts it, pauses are indicative of "cognitive processes" and "changing attentional stages". This is why the present study focuses on pauses to describe the cognitive effort made by translation students. To achieve this aim, the author first discusses the interrelation between pauses and cognitive processes in consideration of the available studies in the literature. Then he attempts to justify why he operationalized number of pauses and length of pauses as research parameters. In "Methods", the author presents his sample of 78 participants, who are the translation students in the Department of Translation and Interpreting in English at Istanbul University. He then presents his data collection tool, the keylogger Translog II, and the source texts - two excerpts from two different user's manual - assigned the participants to translate into Turkish. Lastly, he offers the results as categorized into two sub-titles, number of pauses and length of pauses.

This is the first research to describe Turkish translation students' cognitive efforts and, to the best knowledge of the author, to incorporate the largest sample among the studies intended to investigate translation students' cognitive efforts in view of pauses. The following title is concerned with accounting for the interrelation between these two phenomena, pauses and cognitive effort.

\section{Interplay between pauses and cognitive processes}

What distinguishes translation from an ordinary text production, viz. monolingual text production, is the fact that translated texts are produced based on a source text. Such a premise requires the fulfillment of two basic processes: understanding the source text and producing the target text in line with what has been understood from it. In this 
sense, Dimitrova (2005: 27) lists two likely scenarios. In the first, "the translator reads and comprehends the [source] segment and retrieves and produces [target] linguistic material, without any problems in the process". In the second, "there are one or more problems in the process, in the comprehension of the [source text] and/or in the retrieval and production of [target language] material; this necessitates the application of one or more strategies to solve the problem". She elaborates that pauses occur longer in the second scenario, which is supported by (1996). Schilperoord expresses that "longer pauses reflect cognitive processes that are relatively more effortful" (1996: 11).

From Schilperoord and Dimitrova's statements above, it can be concluded that pauses are behavioral reflections of cognitive processes and longer pauses occurs in the presence of problems with textual production or more effortful cognitive processes. Similarly, Immonen (2006: 315) believes that pauses in text production are indicative of mental organization, problem-solving, or the beginning of a cognitive unit. Mental organization is related to the planning of textual production and may take place before and during the production of a text or its constituent elements such as words, phrases, sentences, and paragraphs. Therefore, as stated above, it requires a translator to make macro-level and micro-level decisions. Yet decision-making may be hampered when a translator encounters a problem, the difficulty of which affects the length of time spent on solving that problem. Immonen's third parameter, "the beginning of a cognitive unit", is crucial for segmentation research. This indicator has been among the most employed parameters of segmentation research (Dragsted, 2005; Dimitrova, 2006; Immonen \& Mäkisalo, 2017), "where pauses are considered as boundaries of translation units or cognitive units, depending on how the segment is determined" Immonen and Mäkisalo (2017: 49).

As Immonen does, Dimitrova (2005: 28) too offers a similar three-item list of mental and behavioral actions, i.e. planning and text generation, applying problem-solving strategies, and monitoring and evaluating already produced TL material. It can be realized that these three practices cover pre-, peri- and post-translation processes. In other words, translators pause before they start translating the source text or a translation segment to plan their text production ahead. They then begin producing their target texts to make as many pauses as needed to plan their translation after making micro-level decision or solve problems by employing their translation knowledge and skills such as strategic, research, and instrumental competencies. After each in-text pause, they resume producing their target texts. Not only when they finish translating but also as they translate, they review and revise their texts to improve them. While pauses made to perform these actions tend to get longer if, for example, the difficulties posed by a source text require more effort to search for a viable solution, they are likely to increase in number if translators encounter more problems than they can handle or their working memory is not strong enough to process relatively larger textual chunks. Therefore, another pause-related parameter besides length of pauses should be operationalized for a more valid evaluation of cognitive effort: number of pauses. For Yamada (2011: 101), the higher the number of pauses is, the more problem-solving activities take place. Thus, number of pauses potentially lends itself to the reasoned interpretation of interruptions in the flow of translation. Hence, two types of pauserelated parameters were operationalized for the purpose of the present study: number of pauses and length of pauses. The following part discusses how these two can be operationalized.

\section{Number and length of pauses and threshold of significance}

Number and length of pauses offer valuable data on the nature of a translation process because they are closely related to textual production "rhythm". "Pauses are of variable length, and a large number of short pauses will likely indicate a different cognitive processing/effort pattern than a single pause of the same overall duration" (Lacruz et al. 2012: 22-23). A relatively higher number of pauses may hint that a translator has spent more time on planning and text production, encountered more problems, and/or reviewed and revised his/her target text more frequently. This parameter also provides data on the text processing capacity of a translator. More pauses hypothetically should correspond with smaller chunks of textual production, which determines the nature of "cognitive rhythm of translators, i.e. 'bursts' of creativity in between pauses" (Saldanha \& O'Brien, 2013: 112). In other words, the more pauses occur during translation, the more frequently cognitive rhythm is interrupted.

Yet the number of pauses on its own does not suffice to pass valid judgements about how pauses relate to cognitive effort. To exemplify, two translators having paused 20 times at the same locations of the same text cannot be claimed to have gone through the same cognitive processes and/or made the same amount of cognitive effort because while one translator's 20 pauses may amount to 300 seconds, the other's may last 150 seconds. It may be assumed from this example that the former has made more cognitive efforts to sort out the same number of translation problems.

However, one major concern about the operationalization of the number of pauses per se may be whether all pauses should be taken into account to describe the progress of a translation and to discuss the cognitive processes translators undergo as they translate since a pause of 5 seconds and another of 15 seconds spent for the same translation problem tell two totally different stories about each translator's cognitive loads. To be specific, a 5second pause in comparison with a 15 -second pause may evidence that a translator in the former case have a higher level of strategic, research, and/or instrumental competence or a more efficient working memory that allows his/her 
to make relatively less cognitive effort to come up with a viable translation solution or to process larger translation segments, respectively. In both scenarios, they can be assumed to put little effort in the solution of that particular problem regardless of the solution's nature. This is why number of pauses and length of pauses should be discussed together.

One crucial consideration about the length is its significance for the analysis. Should every length of pause be included in an analysis intended to describe translators' cognitive load during translation? According to Wengelin (2006: 111) and Koehn (2009: 14), not every pause is significant. Hence, a cutoff value of significance should be set to determine what length of pauses should be included in the analyses. Baaijen et al. (2012) propose two ways to operationalize pauses, i.e. firstly "by imposing a threshold and then defining only the intervals that last longer than this threshold as pauses" (2012: 253). They highlight a problem with such an elimination procedure; it "restricts analysis to longer pauses, which presumably reflect higher-level processes, and ignores the shorter pauses involved in more linguistic processing" (2012: 254). Yet this cannot be considered a matter of concern for the purpose of the present study, for it aims to reveal the "higher-level processes", which are marked by longer pauses.

The attributions like "short(er)" and "long(er)" remain quite relative if not described with observable characteristics. This is why a threshold of significance is needed to come up with working parameters. Van Waes et al. (2009) argue that if researchers wish to observe high-level cognitive processes, they can exclude pauses smaller than 2 seconds from their analyses. But if they intend to investigate "(ir)regularities in interkey intervals", they can use pauses "smaller than 200 milliseconds" (2009: 61). Van Waes et al. (2009: 44) report that the threshold can be "set to 1, 2 or 5 seconds or to any user defined level larger than 1 millisecond" on a keylogging software, i.e. Inputlog, they use. These two studies suggest that each researcher can operationalize varying lengths of pauses depending on the purpose of the study. For example, in the study investigating the performance of human translators assisted by a computer-aided tool, Koehn (2009) categorizes pauses into four: (1) Pauses of less than 2 seconds are thought as a normal part of translation process. (2) Short pauses of 2-6 seconds are indicative of a little hesitation. (3) Medium size pauses of 6-60 seconds point to thinking and planning. (4) Longer pauses than 60 seconds evidence that the translator is stuck and having difficulty solving a particular translation problem (2009: 255). In this categorization, pauses lasting less than 2 seconds are regarded typical of a translation process, thus considered insignificant. It is notable that medium size pauses, i.e. of 6 through 60 seconds, are operationalized as indicators of "thinking and planning". Similarly, Schrijver et al. (2017: 106) considered pauses of 2 seconds and over to determine workable segments. Likewise, based on the available literature, Wengelin (2006: 111) suggests a threshold of 2 seconds.

Krings (1986: 137) marks only the unfilled breaks of at least 3 seconds as problem indicators ${ }^{1}$, while Jakobsen (2003: 90) and Dimitrova (2005: 97) operationalize pauses of at least 5 seconds to create the segmentations for the purposes of their studies. Similarly, PACTE (2005: 613) include the pauses lasting 5 seconds or longer in their analyses. Yamada (2009: 170) too uses pauses of 5 seconds or more to identify translation segments.

In conclusion, the significance of the lengths of pauses varies across works according to their aims. Moreover, including the number of pauses in the analysis is a sine qua non because this parameter is expected to yield reliable data on translators' text processing and producing skills. But the foregoing discussion proves that number of pauses should be analyzed together with length of pauses because the former does not offer data on what could be happening between "bursts of creativity" and on the criticality of a translational issue at stake. As the authors above have done, the author herein is to determine a cutoff value of significance to exclude the pauses likely to be less contributory to the study. In consideration of the thresholds in the abovementioned literature, the author resolved to set a 5-second threshold of significance because he thinks that a pause of 5 seconds is long enough to offer workable information on the nature of pauses.

\section{Methods}

\subsection{Sampling}

The sample of this study was chosen through convenience sampling, which "involves choosing the nearest individuals to serve as respondents and continuing that process until the required sample size has been obtained or those who happen to be available and accessible at the time" (Cohen et al. 2007: 113-114). Thus, the first-, second-, third-, and fourth(last)-year undergraduate students studying in the Department of Translation and Interpreting (in English) at İstanbul University in the 2013-2014 academic year were included in the sample.

\footnotetext{
${ }^{1}$ Als problemindizierend gelten nur ungefüllte Pausen von mindestens drei Sekunden Länge...
} 


\begin{tabular}{|r|c|c|}
\cline { 2 - 3 } \multicolumn{1}{c|}{} & \multicolumn{2}{c|}{ Number of Students } \\
\cline { 2 - 3 } \multicolumn{1}{c|}{} & October $\mathbf{2 0 1 3}$ & May $\mathbf{2 0 1 4}$ \\
\hline $\mathbf{1}^{\text {st }}$ Year & 12 & 9 \\
\hline $\mathbf{2}^{\text {nd }}$ Year & 8 & 9 \\
\hline $3^{\text {rd }}$ Year & 13 & 8 \\
\hline $\mathbf{4}^{\text {th }}$ Year & 10 & 9 \\
\hline Total & $\mathbf{4 3}$ & $\mathbf{3 5}$ \\
\cline { 2 - 3 } & \multicolumn{2}{|c|}{$\mathbf{7 8}$} \\
\hline
\end{tabular}

Table 1. Number of participants in the sample by year-based standing

Table 1 shows that the sample consists of 78 students having been invited to participate in the study in October 2013 and May 2014. 43 students (12 first-, 8 second-, 13 third-, and 10 fourth-year undergraduate students) participated in the first session, i.e. October 2013, whereas the sample in May 2014 consists of 35 students ( 9 first-, 9 second-, 8 third-, and 9 fourth-year undergraduate students). To this best knowledge of the author, this is the largest sampling to investigate the relationship between pauses and cognitive effort of translation students.

\subsection{Data collection}

The author of this study used a keylogger, Translog II, to harvest data from the participants' translations. Although there are other keyloggers, such as ScriptLog and Inputlog, the author opted for Translog II because the former two "are mainly intended for logging and analyzing writing processes, while Translog II is specially designed for the acquisition of data for translation process research" (Carl, 2012: 155). Carl (2012) summarizes its features as recording a translator's keystrokes, classifying keystrokes as "insertion, deletion (delete and backspace), navigation (cursor movements), copy/cut-and-paste, return key, or mouse operations", and logging "the exact time at which each keystroke operation is made" Carl (2012: 155). The recorded timestamps enable "a numerical representation of the pause duration that occurs when typing" (Kumpulainen, 2015: 50).

Another advantageous feature of this software program is that it does not interfere with the text production process as it logs a user's translation process (Carl, 2012: 155; Kumpulainen, 2015: 50; Van Waes et al. 2009: 41). Hence, this non-intrusive nature of keylogging allows researchers to enhance the ecological validity of their data collection procedures (Van Waes et al. 2009: 41; Leijten \& Van Waes, 2013: 358; Albir et al. 2015: 18).

\subsection{Source texts}

The participants were invited to translate two excerpts from two different user's manuals, i.e. of Nikon D60 (a camera) and 2014 Ford escape (a vehicle). The former, consists of 262, was used in October 2013 and the latter of 191 words in May 2014. Both source texts were in English and translated into Turkish on Translog II.

\section{Results}

This study was built on the data concerning two parameters: number of pauses and length of pauses. The data were collected with a keylogging software program, Translog II. This part presents the results on these two parameters.

\subsection{Number of pauses}

This title presents and discusses the findings on number of pauses. Figure 1 presents the number of pauses harvested with Translog II in October 2013 and May 2014. The figure shows that 527, 470, 803, and 838 pauses occur in the renditions of the first-, second-, third-, and fourth-year undergraduate students, respectively. These figures indicate a critical leap in the number of pauses in Year 3 (803 pauses) and a similar number is observable in Year 4 (838 pauses). The numbers of pauses in Year 1 and 2 were calculated to be 527 and 470 pauses, respectively.

The figure also provides a similar increase that occurs in the number of pauses in the May 2014 session. It is clear that the first-, second-, third-, and fourth-year students pause 394, 464, 500, and 684 times, respectively, as they translate the source text. These findings from the October 2013 and May 2014 sessions show that the firstand second-year students pause less frequently than the third- and fourth-year students. 


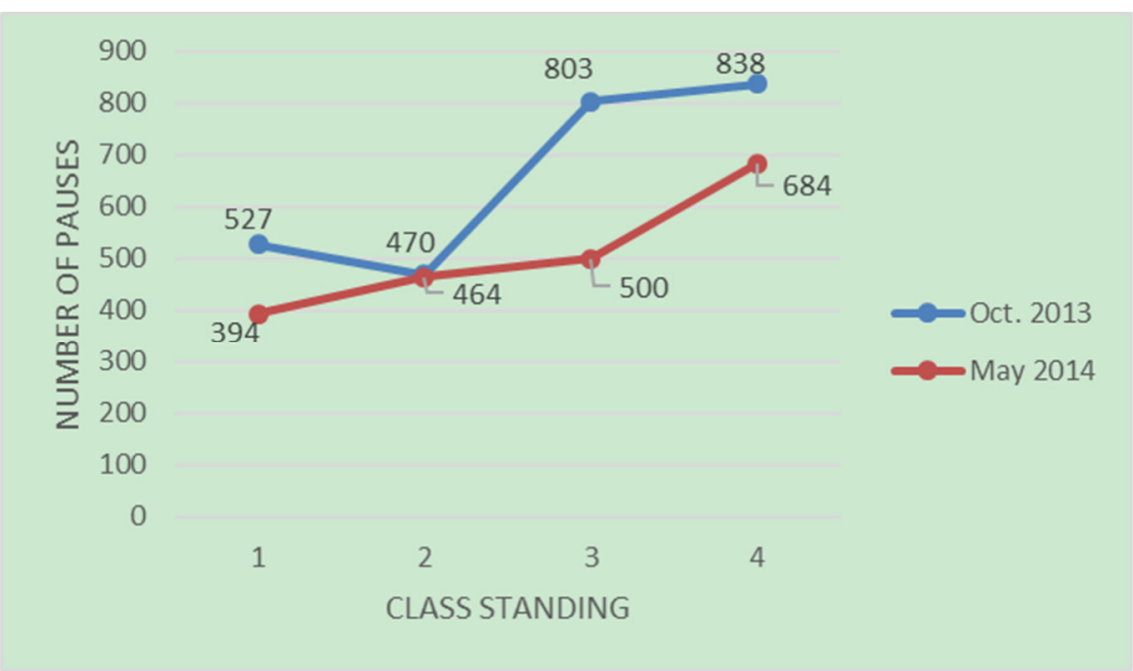

Figure 1. Numbers of pauses in October 2013 and May 2014 by class standing

There is research associating this gradual increase in the number of pauses with improved problem sensitivity. Dimitrova (2005) expresses that "an alternation [occurs] between automated and strategic problem-solving processing" (2005: 53). She elaborates that a high degree of automatized processing at the micro level could result from a lower number of pauses (of experienced translators) (Dimitrova, 2005: 184). On the contrary, EhrensbergerDow \& Massey (2014: 66) have found that professional translators are faster text producers than student translators and they pause more, refer to "resources less often but for longer stretches", thus produce "higher quality translations". The former study suggests that fewer pauses are typical of experienced translators because their translation process is more automatized than student translators, the latter contradicts with this proposition because it reports that professionals pause more, which connotes that non-professionals pause less. Jääskeläinen (1996: 67) reports a similar fast-paced performance in novice translators, who "translate quickly and effortlessly". Jääskeläinen (1996) accounts for this characteristic of novice translators as a component of "developmental hypothesis", in which novice translators problematize less than semi-professionals, e.g. translation students because, as she puts it, the former are "blissfully unaware of their ignorance", while the latter grow more problemsensitive and they develop more awareness of their ignorance. Similarly, in the study comparing 11 students (first-, second- and third-semester students) with 10 professionals to describe measurement of creativity, Gerrit BayerHohenwarter (2011: 687) reports that novice translators have a low degree of problem-sensitivity.

The findings of the present paper substantiate Jääskeläinen (1996: 67)'s developmental hypothesis. In the data collection sessions in October 2013 and May 2014, the fourth-year students were discovered to pause 838 and 684 times, respectively, while the first-year students to perform 527 and 394 pauses in the respective sessions. This may suggest that the novice translators in this study grow more sensitive to translation problems over the course of translation training.

Jääskeläinen (1999, cited by Dimitrova, 2005: 135) also notes that novice translators suffer from a low level of sensitivity to translation problems, which results in novice translators' spending less time on a given translation task than professionals do. This postulates that novice translators exhibit shorter pauses. Therefore, the following part discusses the characterization of translation students' renditions in terms of pause length.

The increased number of pauses may also be an indicator of trainers' overemphasis on "perfect" translation. Students may grow fear of mistakes due to this overemphasis on ideal target text production, which may make them overly doubtful about the probable translation of a source text segment, which is even unlikely to pose a translation problem. This uncertainty may cause them to pause on more source segments and to spend more time on them even when the solution is not as complicated as they think because they may want "to do the job as perfectly as possible" (Dimitrova, 2005: 135). This likely explanation suggests that students in this study may be more concerned about the accuracy of their target texts and have prioritize accuracy over fluency not to make mistakes. Thus, they can be considered to have graduated unready for real-time translation settings that would in most cases require fast delivery and strict observation of deadlines. The next part tackles the length of pauses and may offer more information on the notion of doubt.

\subsection{Length of pauses}

Figure 2 gives a comparative overview of the average lengths of pauses which were observed in October 2013 and May 2014. The figure reveals that a pattern similar to that of the numbers of pauses occurs in relation to the lengths of pauses. In October 2013, the first-, second-, third-, and fourth-year students pause for 20.8, 22.0, 25.4, and 25.3 seconds (rounded) on average, respectively. On the other hand, the average pauses of 14.0, 20.4, 23.5, and 22.9 
seconds (rounded), respectively, were observed in relation to the students having participated in the data collection session in May 2014. That is, the first-year students exhibit shorter lengths of pauses than the fourth-year students and the pause lengths tend to increase over the course of translation training (regardless of the slight difference of mean duration between third-year and fourth-year students in May 2014). In support of the developmental hypothesis above, this finding evidences that novice translators finish a given translation task faster than semiprofessionals, the third- and fourth-year students herein, because they suffer from a lower degree of problemsensitivity and are unaware of this incompetence of theirs. Thus, they spend more time on typing/writing and less on problem solving, which in turn results in faster rendition.

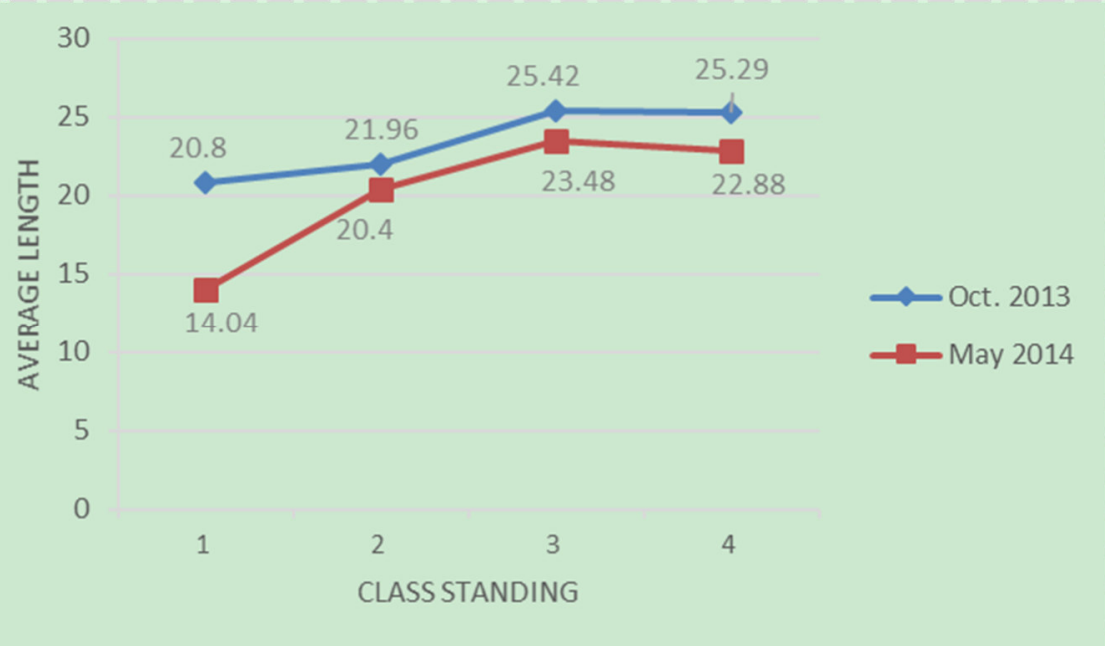

Figure 2. Average lengths of pauses (in seconds) in October 2013 and May 2014

Table 2 indicates that the shortest pause is 5 seconds in October 2013 and May 2014 because the threshold of significance was set to 5 seconds on Translog II. However, it is obvious that the maximum lengths in both sessions are highly variable. In October 2013, the longest pauses were calculated to be $146.8,240.5,309.1$, and 326.2 seconds for the first-, second-, third-, and fourth-year students, respectively. Besides, 138.9, 262.6, 589.8, and 378.7 seconds are the maximum lengths of pauses recorded for the first-, second-, third-, and fourth-year students. It should be noted that the first-year students exhibit the shortest maximum lengths of pauses, 146.8 in October 2013 and 138.9 seconds in May 2014 and the longest pauses recorded by a fourth-year student (326.2 seconds) in October 2013 and a third-year student (589.8 seconds) in May 2014.

\begin{tabular}{|r|c|c|c|c|c|c|c|c|}
\cline { 2 - 9 } \multicolumn{1}{c|}{} & \multicolumn{4}{c}{ October 2013 } & \multicolumn{4}{c|}{ May 2014 } \\
\cline { 2 - 9 } \multicolumn{1}{c|}{} & $\begin{array}{c}\text { Mean } \\
(\mathbf{s e c})\end{array}$ & $\begin{array}{c}\text { Standard } \\
\text { Deviation }\end{array}$ & $\begin{array}{c}\text { Minimum } \\
(\mathbf{s e c})\end{array}$ & $\begin{array}{c}\text { Maximum } \\
(\mathbf{s e c})\end{array}$ & $\begin{array}{c}\text { Mean } \\
\text { (sec) }\end{array}$ & $\begin{array}{c}\text { Standard } \\
\text { Deviation }\end{array}$ & $\begin{array}{c}\text { Minimum } \\
\text { (sec) }\end{array}$ & $\begin{array}{c}\text { Maximum } \\
\text { (sec) }\end{array}$ \\
\hline $\mathbf{1}^{\text {st }}$ Year & 14.0 & 15.5 & 5.0 & 146.8 & 20.8 & 22.5 & 5.1 & 138.9 \\
\hline $\mathbf{2}^{\text {nd }}$ Year & 20.4 & 26.4 & 5.0 & 240.5 & 22.0 & 25.8 & 5.0 & 262.6 \\
\hline $\mathbf{3}^{\text {rd }}$ Year & 23.5 & 32.7 & 5.0 & 309.1 & 25.4 & 41.1 & 5.0 & 589.8 \\
\hline $4^{\text {th }}$ Year & 22.9 & 31.4 & 5.0 & 326.2 & 25.3 & 39.6 & 5.0 & 378.7 \\
\hline Total Mean (sec) & 20.9 & 28.7 & 5.0 & 255.7 & 23.7 & 34.5 & 5.0 & 342.5 \\
\hline
\end{tabular}

Table 2. Lengths of pauses in October 2013 and May 2014

Table 2 also indicates that the mean lengths of total pauses are $20.9 \mathrm{sec}$ and $23.7 \mathrm{sec}$ in October 2013 and May 2014, respectively. These two values are significant for two reasons: the lengths of pauses occurring under the mean lengths of pauses in October 2013 and May 2014 are statistically expected to exhibit a more homogeneous distribution than the ones exceeding them. It can be understood from Table 2 that the mean values of the first- and second-year students in October 2013 and May 2014 are lower than the mean of the total pauses, while the third- and fourth-year students exhibit longer mean pauses. This suggests that the data concerning the pause lengths of the first- and second-year students in both sessions should exhibit a more homogenous distribution than those of the third- and fourth-year students. The distribution of the data is crucial because it may help account for the effect of translation training on students' cognitive processes. 


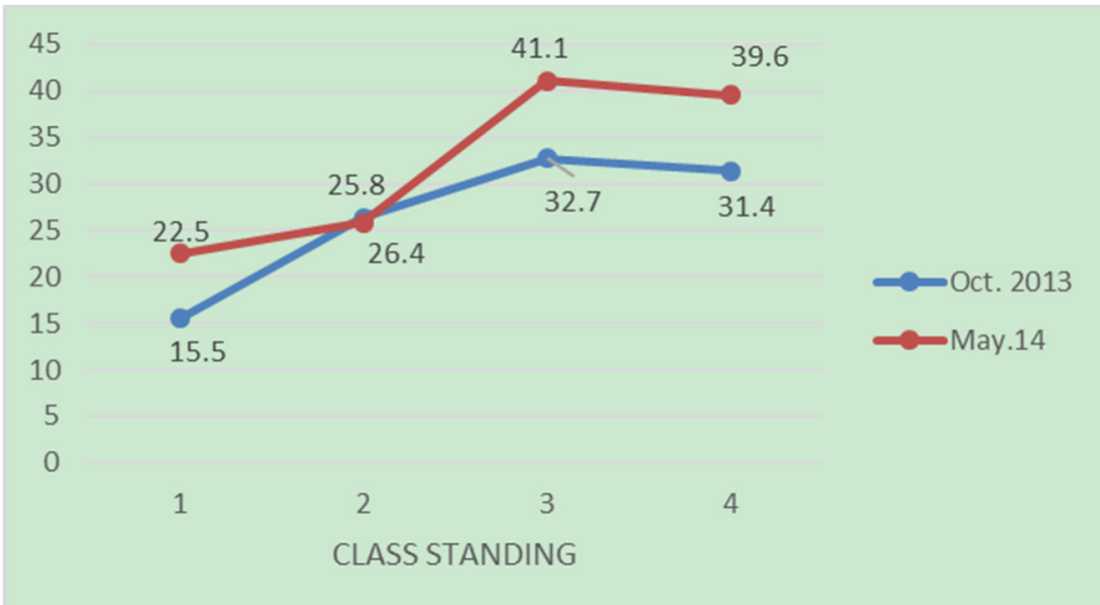

Figure 3. Standard deviation across classes in October 2013 and May 2014

In this study, the standard deviation values of pause lengths were used to describe the diversity of the data concerning the participants' performances. Standard deviation "tells us how spread [normal distribution] is" (Connolly, 2007: 48) and "small standard deviations [...] indicate that data points are close to the mean. A large standard deviation [...] indicates that the data points are distant from the mean" (Field, 2009: 38). Figure 3 presents the standard deviation values concerning the lengths of pauses in October 2013 and May 2014. It is understandable from the figure that the lowest standard deviation values occur in the first-year students, who are followed by the second-years. Besides, it also indicates that the standard deviations gradually increase across the class standings of the participants, from which it can be inferred that the participants' performances get more heterogenous from year 1 through year 4 . This may show that translation training works differently on students and students avail themselves of the offered training differently (Yazıc1, 2011: 89-90), which may result in the development of different strategies to cope with translation problems and in the fact that translation training causes the third- and fourth-year participants of this study to develop more diverse translational behaviours; in other words, the longer translation students are exposed to translation training, the more heterogenous their translational performances get. This finding can be a proof that translation students devote not only more but also varying degrees of cognitive effort to the rendition of a translation segment.

\section{Conclusion}

The present study is the first to reveal Turkish student translators' translation processes in numerical data and one of the few to focus solely on student translators' translation processes rather than comparing the performances of students and professionals. To the best knowledge of the author, another unique characteristic of this study is the size of its sampling, which is the largest of all the studies intended to describe cognitive efforts of translators, be they novice, semi-professional, or professional.

The study is concerned with describing the cognitive efforts that Turkish translation students invest as they translate in consideration of the numbers and lengths of pauses. The results showed that the first-year participants exhibited the fewest and shortest pauses, while the pauses increased in number and length from the first year through the fourth (last). The following minor conclusions were derived in relation to this finding:

(1) In the early stages of their undergraduate education, translation students are less likely to detect translation problems, for they have lower problem sensitivity. Therefore, they pause less, while students in higher classes exhibit more pauses thanks to their higher sensitivity to translation problems.

(2) Due to their lower problem sensitivity and lower awareness concerning the gravity of detected translation problems, students with lower class standings spend less time on solving problems and more on typing than the ones with higher class rank, who are highly sensitive to translation pitfalls and more aware of the severity thereof. (3) Over time, translation students become more doubtful about the accuracy of a source segment that may not even pose a serious problem for them because they are expected to render "perfect" translations. Thus, they spend more time on a translation segment or a solution than needed, which translates into more cognitive effort.

(4) Since translation training works differently on students and students thus develop different strategies toward translation problems, their performances - therefore the degrees of cognitive effort they invest in the course of translation - become more heterogeneous from the first year through the fourth.

These four minor conclusions lead to a major one, i.e. translation students tend to invest not only higher levels of but also varying degrees of cognitive efforts during translation as they are more exposed to translation training.

\section{References}

Albir, A. H., Alves, A., Dimitrova, B. E., \& Lacruz, I. (2015). A retrospective and prospective view of translation 
research from an empirical, experimental, and cognitive perspective: the TREC network. The International Journal for Translation and Interpreting Research, 7(1), 5-25. doi: ti.106201.2015.a02

Baaijen, V. M., Galbraith, D., \& de Glopper, K. (2012). Keystroke Analysis: Reflections on Procedures and Measures. Written Communication, (3)29, 246-277. doi: 10.1177/0741088312451108

Bayer-Hohenwarter, G. (2011). "Creative Shifts" as a Means of Measuring and Promoting Translational Creativity, META, 56(3), 663-692. doi: 10.7202/1008339ar

Carl, M. (2012). Translog-II: A Program for Recording User Activity Data for Empirical Translation Process Research. International Journal of Computational Linguistics and Applications, 3(1), 153-162

Cohen, L., Manion, L., \& Morrison, K. (2007). Research Methods in Education (6th ed.). London: Routledge

Connolly, P. (2007). Quantitative data analysis in education: A critical introduction using SPSS. London: Routledge

Dimitrova, B. E. (2005). Expertise and Explicitation in the Translation Process. Philadelphia: John Benjamins Publishing

Dimitrova, B. E. (2006) Segmentation of the Writing Process in Translation: Experts vs. Novices. In K. P. H. Sullivan \& E. Lindgren (Eds.), Computer Keystroke Logging: Methods and Applications. Oxford: Elsevier, 189-201

Dragsted, B. (2005). Segmentation in translation: differences across levels of expertise and difficulty. Target, 17(1), 49-70. doi: 10.1075/target.17.1.04dra.

Ehrensberger-Dow, M., \& Massey, G. (2014). Cognitive ergonomic issues in professional translation. In J. W. Schwieter \& A. Ferreira (Eds.), The Development of Translation Competence: Theories and Methodologies from Psycholinguistics and Cognitive Science. Cambridge: Cambridge Scholars Publishing, 58-86

Field, A. (2009). Discovering Statistics Using SPSS. London: Sage Publications

Immonen, S. (2006). Translation as a Writing Process: Pauses in Translation Versus Monolingual Text Production. Target, 18(2), 313-335. doi: 10.1075/target.18.2.06imm

Immonen, S., \& Mäkisalo, J. (2017). Pauses Reflecting the Processing of Syntactic Units in Monolingual Text Production and Translation. Hermes - Journal of Language and Communication in Business, 23(44), 45-61. doi: 10.7146/hjlcb.v23i44.97266

Jakobsen, A. L. (2003). Effects of Think Aloud on Translation Speed, Revision and Segmentation, In F. Alves. (Ed.), Triangulating Translation, Amsterdam: John Benjamins Publishing, 69 - 95.

Jääskeläinen, R. (1996). Hard Work Will Bear Beautiful Fruit. A Comparison of Two Think-Aloud Protocol Studies. META, 41(1), 60-74. doi: 10.7202/003235ar

Koehn, P. (2009). A Process Study of Computer-Aided Translation. Machine Translation, 23(4), 241-263. doi: 10.1007/s10590-010-9076-3.

Kumpulainen, M. (2015). On the Operationalisation of 'Pauses' in Translation Process Research. Translation and Interpreting, 7(1), 47-58. doi: ti.106201.2015.a04

Krings, H. P. (1986). Was in den Köpfen von Übersetzern Vorgeht: Eine Empirische Untersuchung zur Struktur des Übersetzungsprozesses an Fortgeschrittenen Französischlernern, Tubingen: Narr

Lacruz, I., Shreve, G. M., \& Angelone, E. (2012). Average Pause Ratio as an Indicator of Cognitive Effort in PostEditing: A Case Study. In S. O’Brien, M. Simard \& L. Specia (Eds.), AMTA 2012 Workshop on Post-Editing Technology and Practice (WPTP 2012). 21-30

Leijten, M. \& Van Waes, L. (2013). Keystroke Logging in Writing Research: Using Inputlog to Analyze and Visualize Writing Processes. Written Communication, 30(3), 358-392.

PACTE. (2005). Investigating Translation Competence: Conceptual and Methodological Issues. META, 50(2), 609 - 619. doi: 10.7202/011004ar

Saldanha, G. \& O’Brien, S. (2013). Research Methodologies in Translation Studies. New York: Routledge

Schilperoord, J. (1996). It's about Time: Temporal Aspects of Cognitive Processes in Text Production. Amsterdam/Atlanta: Rodopi

Schrijver, I., van Vaerenbergh, L., \& van Waes, L. (2017). An Exploratory Study of Transediting in Students' Translation Processes. Hermes - Journal of Language and Communication in Business, 25(49), 99-117. doi: 10.7146/hjlcb.v25i49.97740.

Wengelin, A. (2006). Examining Pauses in Writing: Theory, Methods and Empirical Data. In K. P. H. Sullivan \& E. Lindgren (Eds.), Computer Keystroke Logging: Methods and Applications. Oxford: Elsevier, 107-130

van Waes, L., Leijten, M., \& van Weijen, D. (2009). Keystroke Logging in Writing Research: Observing Writing Processes with Inputlog, Journal of German as a Second Language, 2-3, 41-64

Yamada, M. (2009). A Study of the Translation Process through Translators' Interim Products. Interpreting and Translation Studies, 9, 159-176.

Yamada, M. (2011). Revising Text: An Empirical Investigation of Revision and the Effects of Integrating a TM and MT System into the Translation Process, Unpublished PhD Dissertation, Rikkyo University, Tokyo

Yazıcı, M. (2011). Çeviribilimde Araştırma: Disiplinlerarasılıktan Disiplinlerötesiliğe, İstanbul: Multilingual 